\title{
Successful treatment with low-dose decitabine in acute myelogenous leukemia in elderly patients over 80 years old: Five case reports
}

\author{
JIE LIN, HONGLI ZHU, SUXIA LI, HUI FAN, XUECHUN LU, CHENG CHANG, BO GUO and BING ZHAI \\ Department of Geriatric Hematology, Chinese People's Liberation Army General Hospital, \\ Haidian, Beijing 100853, P.R. China
}

Received October 22, 2012; Accepted January 9, 2013

DOI: $10.3892 / \mathrm{ol} .2013 .1139$

\begin{abstract}
The incidence of acute myelogenous leukemia (AML) in patients over 80 years old is $>20$ times greater than that observed in younger patients. Previously, no standard treatment protocol for elderly patients with AML existed, however the development of hypomethylating agents, including decitabine, has brought about promising results in AML. In the present study, we report on the usage of a lower than routine dosage of decitabine in patients over 80 years old with AML. Since January 2010, 5 patients diagnosed with AML over the age of 80 years old received treatment with decitabine in our hospital. Decitabine was administered at a dose of $10-15 \mathrm{mg} / \mathrm{m}^{2}$ and repeated every other day for a total of 5 days. This cycle was repeated for $\sim 6$ weeks. The 5 patients received a total of 19 cycles of treatment with decitabine. No patient achieved complete or partial remission. An antileukemic effect was observed in $25 \%$ of courses (3/12). An increase in platelet count of $>20 \times 10^{9} / 1$ was observed in $26.3 \%(5 / 19)$ of cycles compared with previous treatment. An increase in hemoglobin concentration of $>20 \mathrm{~g} / \mathrm{l}$ was observed in $36.8 \%$ (7/19) of cycles in comparison to previous treatment, four of which achieved normal hemoglobin levels. One patient became red blood cell transfusion-independent. The median survival time was $19.8 \pm 4.8$ months. Survival time from decitabine administration to mortality was $13.2 \pm 5.1$ months. The main side-effect was bone marrow suppression with grade III-IV thrombocytopenia, grade III-IV leukocytopenia, grade III-IV neutropenia and anemia accounting for $94.7 \%$ (18/19), $47.4 \%$ (9/19), 89.5\% (17/19) and 21.1\% (4/19), respectively. Severe infection or bleeding was not observed and no patient stopped treatment due to adverse effects. In
\end{abstract}

Correspondence to: Dr Hongli Zhu, Department of Geriatric Hematology, Chinese People's Liberation Army General Hospital, 28 Fuxing Road, Haidian, Beijing 100853, P.R. China

E-mail: linjie.online@163.com

Key words: decitabine, acute myelogenous leukemia, methylation, elderly conclusion, extremely low-dose decitabine may be used safely in elderly patients and achieved longer survival times than reported previously in AML patients aged 80 and above. It is suggested that complete remission may not be the primary objective, while improvement of quality of life may be a better choice in AML patients over 80 years old. The cases observed in our study were limited, so more cases are required for further study.

\section{Introduction}

The incidence of acute myelogenous leukemia (AML) in the elderly population is increasing due to the aging of the general population. Statistics from U.S. National Cancer Institute demonstrated that the incidence of AML is 23/100,000 in the age range of $80-84$ years, while $21.2 / 100,000$ over the age of 85 , which is 20 times greater than the incidence in younger patients (1). The biological characteristics, clinical manifestations and treatment response of AML in elderly individuals differs from that in young patients. The major characteristics of AML in elderly patients include: i) high incidence of cytogenetic abnormalities (2-5); ii) high incidence of therapy-related leukemia; iii) association with a prior hematological disease (6); iv) often accompanied by multidrug resistance gene expression (3); v) high incidence of comorbidity and poor tolerance to chemotherapy (7). All of these features contribute to low remission and short survival times. There are no standard treatment regimens for AML in elderly patients. Intensive chemotherapy is not suitable for the treatment of AML in patients over 80 years old (8). Common regimens such as low-dose cytarabine chemotherapy and the best supportive care alone do not prolong survival times significantly in elderly patients. The mean survival time of patients with AML over 80 years old is $\sim 3$ months (9). Therefore, the treatment regimens for elderly patients with AML has evolved from chemotherapy only to targeted therapies. The new drugs under investigation include: humanized anti-CD33 monoclonal antibodies (10), tyrosine kinase inhibitors (11), 5-azacytidine (12), 5-aza-2'-deoxycytidine $(13,14)$, proteasome inhibitors (15), anti-angiogenic drugs (16), FLT3 inhibitors (17) and anti-apoptotic inhibitors (18). Among them, decitabine is a demethylating agent. 
Decitabine is also known as 5-aza-2'-deoxycytidine, which is a 2'-deoxycytidine analog. Previous studies have demonstrated that decitabine induces cytotoxicity at high concentrations and demethylation at low concentrations. Decitabine normalizes the demethylation status of cancer suppressor genes by inhibition of DNA methyltransferase-1 (DNMT1), as well as normalizing terminal differentiation, the aging process or apoptosis of cells. In 1992, Zagonel et al reported that low-dose decitabine was effective in myelodysplastic syndrome (MDS) and this finding was confirmed in further clinical trials $(19,20)$. Subsequently, the indications for decitabine have been expanded from MDS to AML, chronic myelogenous leukemia and chronic myelomonocytic leukemia $(21,22)$. In previous studies, different degrees of hypermethylation have been identified in leukemia, which are correlated with the development of drug resistance (23). Therefore, demethylation has become the treatment target of leukemia. Currently, most clinical trials for decitabine include only a few patients aged 80 years and above. In addition, the tolerance, efficacy and side-effect profile of decitabine in the Chinese elderly population with AML is unclear due to ethnic differences. The dosage, efficacy and safety of decitabine in this population requires more research. This study observes the short-term efficacy and side-effect profile of decitabine in patients with AML over 80 years old.

\section{Patients and methods}

Patients. Five elderly patients aged over 80 years old with AML were enrolled in January 2010 and treated with decitabine in the Department of Geriatric Hematology in the People's Liberation Army General Hospital (Beijing, China). The study was approved by the Ethics Committee of The Chinese PLA General Hospital, Beijing, China. Written informed consent was obtained from the patients priort to the study.

Treatment. Decitabine (Janssen Pharmaceuticals, Xi'an, China) was administered at a dose of $10-15 \mathrm{mg} / \mathrm{m}^{2}$ by continuous intravenous infusion over $1 \mathrm{~h}$ and repeated every other day for a total of 5 days. Each cycle was repeated every 6 weeks. No other chemotherapy was provided from administration of decitabine to mortality. Hematopoietic colony-stimulating factors were used during bone marrow suppression. Supportive care measures included the use of red blood cell transfusion in patients with a hemoglobin level $<8 \mathrm{~g} / \mathrm{dl}$ and platelet transfusion in patients with a platelet count $<20 \times 10^{9} / 1$ or where active bleeding existed.

Efficacy and side-effect assessment. Blood routine, liver and kidney function tests, chest X-ray, echocardiography, cardiac enzymes and electrocardiograms were performed prior to and following treatment. Bone marrow examination was performed following some cycles of treatment.

Treatment efficacy was evaluated according to the following: i) complete remission (CR): blast cell levels in the bone marrow of $<5 \%$, platelet levels of $>100 \times 10^{9} / 1$, white blood cell (WBC) levels of $>1.5 \times 10^{9} / 1$ and absence of extramedullary infiltration. ii) Partial remission (PR): either blast cell levels in the bone marrow between $5-25 \%$, platelet levels of $>100 \times 10^{9} / 1$ and WBC levels of $>1.5 \times 10^{9} / 1$ or blast cell levels in the bone marrow of $<5 \%$ but platelet levels of $<100 \times 10^{9} / \mathrm{L}$ and $\mathrm{WBC}$ levels of $<1.5 \times 10^{9} / 1$. iii) Antileukemic effect (ALE): blast cells in the bone marrow reduced by $>25 \%$ compared with before treatment, but do not meet PR criteria. iv) Progressive disease (PD): blast cells in the peripheral blood or bone marrow increase $>25 \%$ compared with before treatment. v) Stable disease (SD): other than CR, PR, ALE and PD.

The side-effects of chemotherapy were graded according to WHO criteria: grade 0 , grade I, grade II, grade III and grade IV.

Statistical analysis. Numerical data are reported as mean \pm standard deviation and were analyzed with the Student's t-test (pair-wise comparison for pre- and posttreatment comparison). Event rate was analyzed using the Chi-square test. $\mathrm{P}<0.05$ was considered to indicate a statistically significant result.

\section{Results}

General data. The clinical information of the 5 patients is presented in Table I. All patients were in relapse or refractory status. Five patients received 19 cycles of treatment with decitabine, mean of which was 4 cycles (range, 3-5 cycles).

Therapeutic efficacy. Bone marrow examination was performed following 12 cycles of treatment. No patients achieved CR or PR. ALE was observed in $25 \%$ of courses (3/12). An increase in platelet count of $>20 \times 10^{9} / 1$ was observed in $26.3 \%$ (5/19) of cycles compared with previous treatment. The mean time to achieve platelet best response was 35.6 days. An increase in hemoglobin concentration of $>20 \mathrm{~g} / \mathrm{l}$ was observed in $36.8 \%$ (7/19) of cycles in comparison to previous treatment, four of which achieved normal hemoglobin levels. The mean time to best hemoglobin response was 35.4 days. One patient became red blood cell transfusionindependent.

Median survival time was $19.8 \pm 4.8$ months (Table I), which was considerably longer than previous studies in elderly AML patients treated with decitabine (24-27) (Table II). The survival time from decitabine administration to mortality was 13.2 \pm 5.1 months (Table I).

Adverse effects. The main side-effect was bone marrow suppression. The lowest value and days to the lowest value of blood routine tests are presented in Table III. Grade III-IV thrombocytopenia, grade III-IV leukocytopenia, grade III-IV neutropenia and anemia accounted for $94.7 \%$ (18/19), $47.4 \%$ (9/19), 89.5\% (17/19) and $21.1 \%$ (4/19) of side-effects, respectively. Severe infection or bleeding was not observed. No other grade III-IV side-effects were observed. No patient discontinued treatment due to side-effects.

\section{Discussion}

Abnormalities in DNA methylation play an important role in the development of hematological malignancy. Decitabine, a hypomethalyting agent, reverses hypermethylation of genes in vitro. Reversal of aberrant methylation leads to re-expression of silenced tumor suppressor genes. In 2006, 
Table I. Clinical information of patients.

\begin{tabular}{|c|c|c|c|c|c|c|c|c|}
\hline No. & Gender & $\begin{array}{c}\text { Age } \\
\text { (years) }\end{array}$ & Classification & $\begin{array}{l}\text { Charlson } \\
\text { comorbidity index }\end{array}$ & $\begin{array}{c}\text { Chromosome } \\
\text { karyotypes }\end{array}$ & $\begin{array}{l}\text { Duration of prior } \\
\text { MDS (months) }\end{array}$ & $\begin{array}{l}\text { Survival }^{\mathrm{a}} \\
\text { (months) }\end{array}$ & $\begin{array}{l}\text { Survival }^{\mathrm{b}} \\
\text { (months) }^{\text {month }}\end{array}$ \\
\hline 1 & Male & 87 & AML-M6 & 3 & $46 X Y$ & 15 & 14 & 16 \\
\hline 2 & Male & 86 & AML-M2 & 2 & $46 X Y$ & - & 8 & 27 \\
\hline 3 & Male & 85 & AML-M4 & 2 & $46 X Y$ & 30 & 19 & 21 \\
\hline 4 & Male & 80 & AML-M4 & 1 & $45 X,-Y$ & - & 8 & 15 \\
\hline 5 & Female & 82 & AML-M4 & 3 & $46 X X$ & & 17 & 20 \\
\hline
\end{tabular}

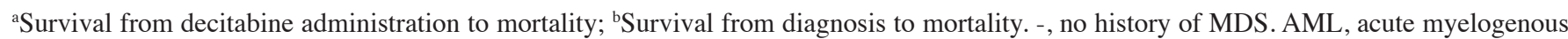
leukemia; MDS, myelodysplastic syndrome.

Table II. Regimen of decitabine in elderly AML patients and efficacy.

\begin{tabular}{|c|c|c|c|c|c|}
\hline Authors (Ref.) & Cases & $\begin{array}{l}\text { Mean age } \\
\text { (years) }\end{array}$ & Dosage & $\begin{array}{l}\text { Response } \\
\text { rate }(\%)\end{array}$ & $\begin{array}{l}\text { Survival } \\
\text { (months) }\end{array}$ \\
\hline Cashen, et al (24) & 55 & 74 & $20 \mathrm{mg} / \mathrm{m}^{2}$ x 5 days & 25 & 7.7 \\
\hline Blum, et al (25) & 53 & 74 & $20 \mathrm{mg} / \mathrm{m}^{2}$ x 10 days & 61 & 13.0 \\
\hline Lübbert, et al (26) & 227 & 72 & $\begin{array}{l}15 \mathrm{mg} / \mathrm{m}^{2} \mathrm{q} 8 \mathrm{~h} \text { x } 3 \text { days } \\
\text { ATRA } 45 \mathrm{mg} / \mathrm{m}^{2} \times 28 \text { days }\end{array}$ & 26 & 5.5 \\
\hline Garcia-Manero, et al (27) & 54 & 60 & $\begin{array}{l}15 \mathrm{mg} / \mathrm{m}^{2} \times 10 \text { days } \\
\text { Valprolic acid }\end{array}$ & 22 & 6.0 \\
\hline
\end{tabular}

AML, acute myelogenous leukemia; ATRA, all trans-retinoic acid.

Table III. Blood routine changes following decitabine treatment (mean $\pm \mathrm{SD})$.

\begin{tabular}{lcc}
\hline Component & $\begin{array}{c}\text { Lowest value } \\
\text { after treatment }\end{array}$ & $\begin{array}{c}\text { Days to the } \\
\text { lowest value } \\
\text { after treatment }\end{array}$ \\
\hline Platelet & $19.6 \pm 15.6\left(\times 10^{9} / 1\right)$ & $12.9 \pm 9.0$ \\
White blood cell & $2.7 \pm 2.5\left(\times 10^{9} / 1\right)$ & $14.1 \pm 7.9$ \\
Absolute neutrophil count & $0.5 \pm 0.5\left(\times 10^{9} / 1\right)$ & $17.7 \pm 10.0$ \\
Hemoglobin & $84.9 \pm 7.6(\mathrm{~g} / \mathrm{l})$ & $12.4 \pm 10.2$ \\
\hline
\end{tabular}

the US FDA approved decitabine for the indication of MDS. The efficacy of low-dose decitabine in the treatment for MDS laid the foundation for AML treatment research. Decitabine to treat AML has been evaluated in a number of clinical trials, however these only included a few patients aged 80 years and above.

Elderly patients with AML cannot tolerate either hematopoietic stem cell transplantation or standard intensity chemotherapy. Therefore, regimens with a lesser degree of side-effects are recommended. Furthermore, there is no standard treatment regimen for elderly AML patients. Treatment should be individualized based on the nature of the disease, the physiological status of the patient and the patient's preferences. We consider that CR may not be the primary objective, while improvement of life quality may be a better choice (9). According to this therapeutic goal, we modified the routine regimen of decitabine. Firstly, the single dose of decitabine was reduced. The total dose equaled 1/2-3/4 of the dose used in routine regimens. Secondly, the administration of decitabine was changed to q.o.d. in order for the adverse effects to be observed sufficiently. Reinforcement of supportive care is also a critical part of treatment. Our study demonstrated that decitabine increases thrombocyte and hemoglobin levels and reduces blast cell levels to some extent in some patients, although none of the patients achieved PR or CR. In particular, the mean survival of the 5 patients was 19.8 months, which is significantly longer than the survival reported for AML patients aged 80 and above $(28,29)$. It is suggested that, although the present decitabine dosage cannot suppress blast cell to normal levels, it may slow down the growth of blast cells. Therefore, although patients do not achieve remission over a long period, disease progression is not rapid.

The main adverse effect of decitabine in elderly patients was bone marrow suppression, most notably in thrombocytopenia and neutrocytopenia. This often occurred 2 weeks following treatment. No severe bleeding or infection was observed following reinforcement of supportive care. If strong supportive care is provided, administration of decitabine in elderly patients is relatively safe.

The cases observed in our study were limited, hence a comprehensive conclusion cannot be made. More cases are required for further study to confirm the results. 


\section{Acknowledgements}

This study was supported by The Special Funds for Central Health Projects (No. B2009B115), Innovation Funds in PLA General Hospital (No. 12KMM34) and Clinical Research Supportive Funds in PLA General Hospital (No. 2012FC-TSYS-1020).

\section{References}

1. Altekruse SF, Kosary CL, Krapcho M, et al: SEER Cancer Statistics Review, 1975-2007. Bethesda,MD, National Cancer Institute, 2010. Available at http://seer.cancer.gov/csr/1975_2007/.

2. Pagano L, Mele L, Casorelli I, et al: Acute lymphoblastic leukemia in the elderly. A twelve-year retrospective, single center study. Haematologica 85: 1327-1329, 2000.

3. Leith CP, Kopecky KJ, Godwin J, et al: Acute myeloid leukemia in the elderly: assessment of multidrug resistance (MDR1) and cytogenetics distinguishes biologic subgroups with remarkably distinct responses to standard chemotherapy. A Southwest Oncology Group study. Blood 89: 3323-3329, 1997.

4. Hiddemann W, Kern W, Schoch C, et al: Management of acute myeloid leukemia in elderly patients. J Clin Oncol 17: 3569-3576, 1999.

5. Wahlin A, Markevärn B, Golovleva I and Nilsson M: Prognostic significance of risk group stratification in elderly patients with acute myeloid leukaemia. Br J Haematol 115: 25-33, 2001.

6. Gajewski JL, Ho WG, Nimer SD, et al: Efficacy of intensive chemotherapy for acute myelogenous leukemia associated with preleukemic syndrome. J Clin Oncol 7: 1637-1645, 1989.

7. Pedersen-Bjergaard J, Ersbøll J, Sørensen HM, et al: Risk of acute nonlymphocytic leukemia and preleukemia in patients treated with cyclophosphamide for non-Hodgkin's lymphomas: comparison with results obtained in patients treated for Hodgkin's disease and ovarian carcinoma with other alkylating agents. Ann Intern Med 103: 195-200, 1985.

8. Kantarjian H, O'brien S, Cortes J, et al: Results of intensive chemotherapy in 998 patients age 65 years or older with acute myeloid leukemia or high-risk myelodysplastic syndrome. Cancer 106: 1090-1098, 2006.

9. Lin J, Zhu HL, Lu XC, et al: Clinical analysis of 12 acute leukemia patients aged over 80 years. Zhongguo Shi Yan Xue Ye Xue Za Zhi 19: 139-142, 2011 (In Chinese).

10. Bross PF, Beitz J, Chen G, et al: Approval summary: gemtuzumab ozogamicin in relapsed acute myeloid leukemia. Clin Cancer Res 7: 1490-1496, 2001.

11. Kindler T, Breitenbuecher F, Marx A, et al: Efficacy and safety of imatinib in adult patients with c-kit-positive acute myeloid leukemia. Blood 103: 3644-3654, 2004

12. Silverman LR, Demakos EP, Peterson BL, et al: Randomized controlled trial of azacitidine in patients with the myelodysplastic syndrome: a study of the cancer and leukemia group B. J Clin Oncol 20: 2429-2440, 2002.

13. Lübbert M: DNA methylation inhibitors in the treatment of leukemias, myelodysplastic syndromes and hemoglobinopathies: clinical results and possible mechanisms of action. Curr Top Microbiol Immunol 249: 135-164, 2000.
14. Rüter B, Wijermans PW and Lübbert M: DNA methylation as a therapeutic target in hematologic disorders: recent results in older patients with myelodysplasia and acute myeloid leukemia. Int J Hematol 80: 128-135, 2004.

15. Yu C, Rahmani M, Dent P and Grant S: The hierarchical relationship between MAPK signaling and ROS generation in human leukemia cells undergoing apoptosis in response to the proteasome inhibitor Bortezomib. Exp Cell Res 295: 555-566, 2004.

16. Fiedler W, Mesters R, Tinnefeld H, et al: A phase 2 clinical study of SU5416 in patients with refractory acute myeloid leukemia. Blood 102: 2763-2767, 2003.

17. Stirewalt DL and Radich JP: The role of FLT3 in haematopoietic malignancies. Nat Rev Cancer 3: 650-665, 2003.

18. Marcucci G, Byrd JC, Dai G, et al: Phase 1 and pharmacodynamic studies of $\mathrm{G} 3139$, a Bcl-2 antisense oligonucleotide, in combination with chemotherapy in refractory or relapsed acute leukemia. Blood 101: 425-432, 2003.

19. Zagonel V, Lo Re G, Marotta G, et al: 5-Aza-2'-deoxycytidine (decitabine) is an effective agent for the treatment of advanced myelodysplastic syndromes (MDS). Proc Am Soc Clin Oncol 11: 226, 1992 (abstr).

20. Pinto A and Zagonel V: 5-Aza-2'deoxycytidine (decitabine) and 5 -azacytidine in the treatment of acute myeloid leukemias and myelodysplastic syndromes: past, present, and future trends. Leukemia 7 (Suppl 1): 51-60, 1993.

21. Wijermans PW, Rüter B, Baer MR, et al: Efficacy of decitabine in the treatment of patients with chronic myelomonocytic leukemia (CMML). Leuk Res 32: 587-591, 2008.

22. Issa JP, Gharibyan V, Cortes J, et al: Phase II study of low-dose decitabine in patients with chronic myelogenous leukemia resistant to imatinib mesylate. J Clin Oncol 23: 3948-3956, 2005.

23. Claus R and Lübbert M: Epigenetic targets in hematopoietic malignancies. Oncogene 22: 6489-6496, 2003.

24. Cashen AF, Schiller GJ, O'Donnell MR and DiPersio JF: Multicenter, phase II study of decitabine for the first-line treatment of older patients with acute myeloid leukemia. J Clin Oncol 28: 556-561, 2010.

25. Blum W, Garzon R, Klisovic RB, et al: Clinical response and miR-29b predictive significance in older AML patients treated with a 10-day schedule of decitabine. Proc Natl Acad Sci USA 107: 7473-7478, 2010.

26. Lübbert M, Rüter B, Claus R, et al: A multicenter phase II trial of decitabine as first-line treatment for older AML patients with acute myeloid leukemia judged unfit for induction chemotherapy. Haematologica 97: 393-401, 2012.

27. Garcia-Manero G, Kantarjian HM, Sanchez-Gonzalez B, et al: Phase 1/2 study of the combination of 5-aza-2'-deoxycytidine with valproic acid in patients with leukemia. Blood 108: 3271-3279, 2006.

28. DeLima M, Ghaddar H, Pierce S and Estey E: Treatment of newly diagnosed acute myelogenous leukaemia in patients aged 80 years and above. Br J Haematol 93: 89-95, 1996.

29. Latagliata R, Alimena G, Carmosino I, et al: Conservative treatment for patients over 80 years with acute myelogenous leukemia. Am J Hematol 71: 256-259, 2002. 